Supporting Information

\title{
Photochemical Stability of Pentacene and a Substituted Pentacene in Solution and in
}

\section{Thin Films.}

Ashok Maliakal,* Krishnan Raghavachari, ${ }^{\dagger}$ Howard Katz, Edwin Chandross and Theo

Siegrist.

Bell Laboratories, Lucent Technologies, 600 Mountain Avenue, Murray Hill, NJ 07974

and ${ }^{\dagger}$ Department of Chemistry, Indiana University, Bloomington, IN 47405

Figure S-1. X-Ray Diffractogram for a film of 6,13

bis(triisopropylsilylethynyl)pentacene on quartz. Lines at $d=16.86 \AA$ and $5.62 \AA$ indicate crystallinity in the thin film. The broad feature with a maximum at $\sim 22$ degrees is typical for quartz. The layer spacing of $16.86 \AA$ is in close agreement with the value of 16.83 A reported by Anthony et. al. (J. Am. Chem. Soc. 2001, 9482-9483).

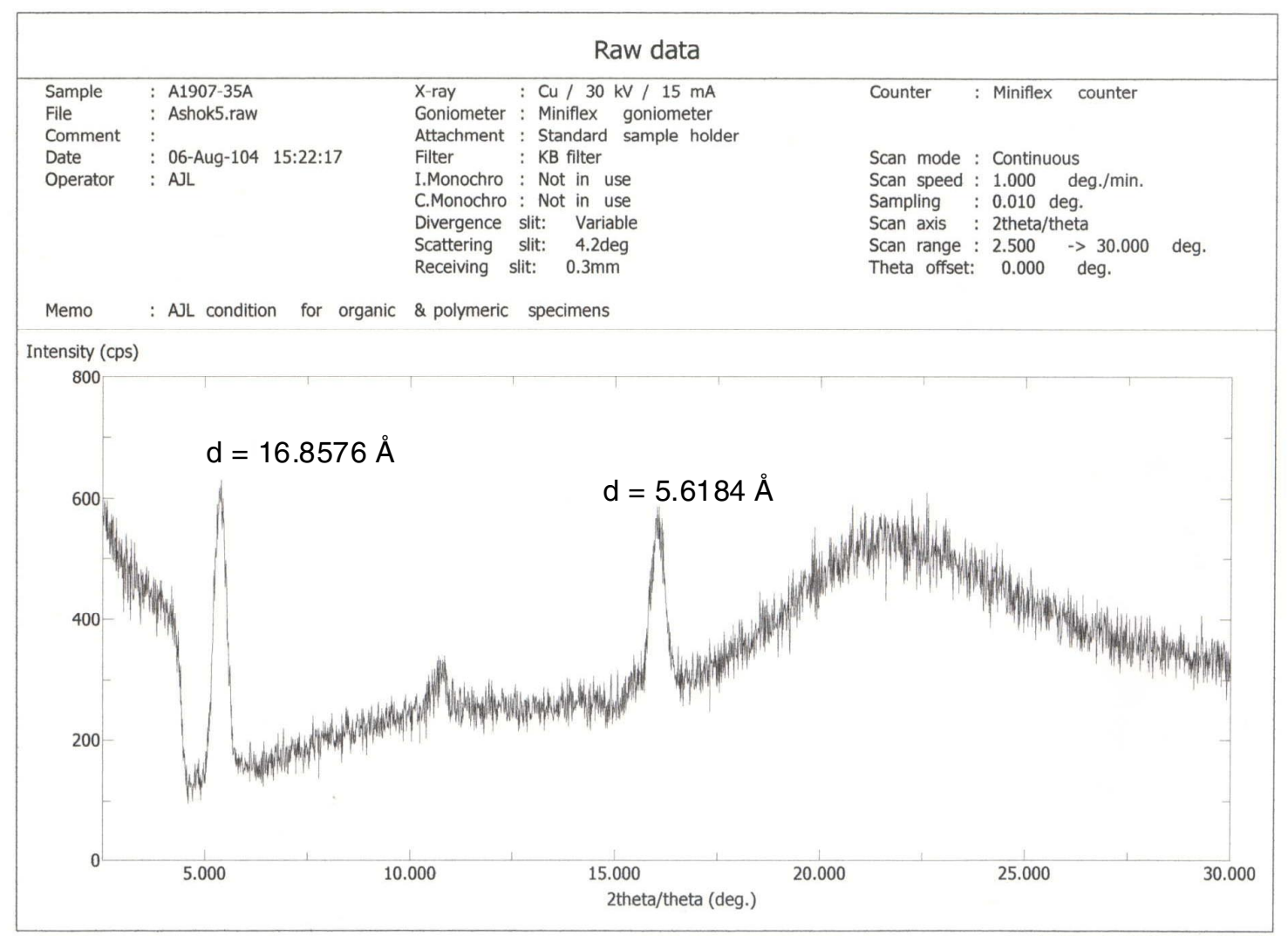

2004 Aug 6 15:22:27 Page-1 